\title{
Climate Change and Biosphere Response: Unlocking the Collections Vault
}

\author{
KENNETH G. JOHNSON, STEPHEN J. BROOKS, PHILLIP B. FENBERG, ADRIAN G. GLOVER, KAREN E. JAMES, \\ ADRIAN M. LISTER, ELLINOR MICHEL, MARK SPENCER, JONATHAN A. TODD, EUGENIA VALSAMI-JONES, JEREMY \\ YOUNG, AND JOHN R. STEWART
}

\begin{abstract}
Natural history collections (NHCs) are an important source of the long-term data needed to understand how biota respond to ongoing anthropogenic climate change. These include taxon occurrence data for ecological modeling, as well as information that can be used to reconstruct mechanisms through which biota respond to changing climates. The full potential of NHCs for climate change research cannot be fully realized until high-quality data sets are conveniently accessible for research, but this requires that higher priority be placed on digitizing the holdings most useful for climate change research (e.g., whole-biota studies, time series, records of intensively sampled common taxa). Natural history collections must not neglect the proliferation of new information from efforts to understand how present-day ecosystems are responding to environmental change. These new directions require a strategic realignment for many NHC holders to complement their existing focus on taxonomy and systematics. To set these new priorities, we need strong partnerships between NHC holders and global change biologists.
\end{abstract}

Keywords: global change, museums, biodiversity informatics, ecological modeling, phenology

$\mathbf{H}^{\circ}$ ow the living world will respond to climate change is widely recognized as one of the most pressing questions for biologists today (McCarty 2001, Walther et al. 2002, Thomas et al. 2004), but research progress is often limited by a lack of long-term data sets from which to extract patterns and test predictions (Willis and Birks 2006). Long-term data are required because biotic responses exhibit threshold effects and nonlinear dynamics (Andersen et al. 2009, Kuussaari et al. 2009), and because infrequent events such as floods or hurricanes might be critical factors controlling the distribution and functioning of ecosystems (Woodley 1992). They are also necessary to distinguish signals of anthropogenic change (such as climate change and environmental change) from natural variability.

Over the past few decades, ecologists have been using data from repeated surveys, time-series stations, and other monitoring activities to study the biotic response to climate change (e.g., Eggleton et al. 2009). Such surveys are the most powerful tools we have for finding correlations between biotic changes and climate change; however, the numbers of these surveys and their duration have been limited, and funding has often been intermittent. For many questions, data of this type are simply unavailable, and alternative sources of data must be creatively repurposed. Historical records provide a second source of temporal information on biotic change; these include diaries and memoirs, collection logs, official catch or hunting records, personal memories, ships' logs, photographs, and paintings and other images of landscape or biota. Such sources recently have been mined for information in ways previously unexplored (Wheeler and García-Herrera 2008).

Natural history collections (NHCs), held worldwide in museums and research institutions, provide a third valuable set of resources for climate change research (Pyke and Ehrlich 2010). These collections hold billions of specimens collected over the past two centuries, each potentially witness to past ecological conditions and irrefutable evidence of historical biogeographic distributions (Krishtalka and Humphrey 2000). These collections have evolved ad hoc in response to changing institutional collecting priorities. Most were assembled to serve research in taxonomy, systematics, and biogeography, and were supplemented by material obtained through the opportunistic acquisition of donations, rescue of orphaned collections, and purchase of specimens for exhibition. This history presents opportunities and barriers to the use of NHCs in research on biotic response to climate change. One advantage is that NHCs typically have broad taxonomic and geographic coverage, and often include material obtained through repeated collecting over long periods using a variety of methods. These complementary collections are usually held by multiple institutions and will require enhanced tools for discovery 
and integration. Existing NHCs can possibly provide a more complete sampling of biotic diversity than other sources; some examples of NHC resources are published systematic works and floral and faunal lists, unpublished reports, new survey observations, or new collections (Mikkelsen and Bieler 2000). Moreover, study of NHCs can inform the need for new surveys and suggest areas to be resampled, information that is invaluable when resources are limited and the need for results is urgent (Guralnick and Van Cleve 2005).

Collections constitute a unique source of material that might be critical to solving particular problems and that cannot be re-collected for practical or ethical reasons. Significant specimens might include extinct or endangered taxa (Bastos-Silveira and Lister 2007), collections from primary habitats that have since degraded, or those that cannot be replicated because of economical or political restrictions (Gaubert et al. 2006). The long history of collections also allows present-day researchers to study morphological, biochemical, and geochemical records of early or even preindustrial conditions (Miller and Waites 2003, Hilton et al. 2006). In addition, existing collections can function as sources of material for pilot studies or for integrated projects that would not be feasible if they were forced to rely solely on new collecting initiatives (McElwain and Chaloner 1995).

In this article, we briefly summarize the relevant kinds of information that can be extracted from collections and describe how to enhance the contribution of NHCs to understanding how the biosphere responds to climate change. A comprehensive review and analysis of much of this literature can be found in Pyke and Ehrlich (2010). We focus on the biotic response to climate change rather than the equally important use of NHCs as a source of proxy data to reconstruct past climate conditions. In our view, strong partnerships must be developed between NHC holders and new NHC users; we highlight some of the technological and cultural challenges to be overcome and the mutual benefits to be gained as these partnerships grow in the coming decades. Given the increasingly tight fiscal environment in which NHCs must operate, it is imperative that collection holders be proactive in maximizing their role and contributions in the ever more important field of climate change research. In this way they may demonstrate the continuing scientific value of NHCs to developing research agendas and open new sources of funding to enhance the contribution of NHCs to global change studies.

\section{Collections as historical records of species occurrences}

An NHC specimen with associated data (locality, collection date, context, etc.) is an unambiguous record of the occurrence of a taxon at a particular place and time. Data backed by specimen vouchers are always preferable to nonvouchered occurrence records because specimens can be used to verify and update taxonomic determinations, especially when taxon concepts have changed significantly in the intervening years. Many studies of changes to species' ranges use historical occurrence records extracted from NHCs, employing data extracted from collections directly or secondary sources derived from collections data, such as taxonomic monographs and check lists or Web-served aggregated databases (Parmesan et al. 1999, Tingley and Beissinger 2009). Collections data need not be perfectly resolved to provide a crucial insight on biotic change, and repeated samples forming time series within collections are not always required to test changes in species ranges; some questions can be addressed with historical point records that demonstrate baseline conditions. For example, records from existing NHCs with detailed sampling information have been compared with data from resampling efforts to document shifts in the altitudinal distribution of small-mammal species in Yosemite National Park (California) between the early 20th and early 21st centuries (Moritz et al. 2008), and moth assemblages on Mount Kinabalu (Malaysia) between 1965 and 2007 (Chen et al. 2009). Historical occurrence records also can be used to determine whether an apparently recent immigrant species is in fact a longtime resident (Frey 2009).

Data from past changes in distribution can be used to model future responses. Historical distributions and environmental data can be used to test ecological niche models, which may be used to forecast biotic response under different future climate change scenarios (Peterson et al. 2002, Broennimann et al. 2006, Tingley and Beissinger 2009). These models are then run forward to the present to compare the resulting predictions with known current distributions. This approach was used to test models of butterfly distribution change in Canada (Kharouba et al. 2009), integrating species-occurrence data from NHCs and other sources with historical instrumental records of environmental data. In principle, both the biotic and environmental data required to complete historical tests of ecological models can be obtained from NHCs if geochemical or biochemical proxy data are extracted from material held in collections.

Natural history collections can provide insights into extinction rates in response to climate change. Significant lags can occur between environmental response and distribution change; for instance, for taxa with long generation times, when long-lived adults are not sensitive to change but other life stages are affected, or when ecological interactions within a community result in threshold effects (CCSP 2009). "Extinction debt" is a result of this sort of response, in which drivers of extinction such as habitat change occur rapidly but declining populations persist for long periods before becoming extinct (Kuussaari et al. 2009). An important priority for conservation biologists is to estimate extinction debt, but the empirical evidence required to do so is limited. Tracking the fate of species that suffered total extinction in the past can help researchers understand this type of biotic sensitivity to change. An intensive program of high-precision accelerator mass spectrometry radiocarbon dating of specimens stored in NHCs showed that climate change led to complex range changes and fragmentation preceding the extinction of 
woolly mammoth, Mammuthus primigenius, and giant deer, Megaloceros giganteus. Each species ultimately contracted into a different final refugium where, after several thousand years, it finally succumbed to local pressures (Lister and Stuart 2008).

\section{Beyond taxon distributions: Records of ecological process from NHCs}

Collections are much more than just gold-standard occurrence records; specimens therein can provide a rich suite of ecological, morphological, and biochemical data. For example, NHCs have been used to test predictions derived from ecophysiological "rules" that describe correlation between body size and climate (Millien et al. 2006). Likewise, researchers can test phenological reactions of populations to climate change (Parmesan 2007). Classic studies of phenological changes such as the timing of birds' egg laying and migration, insect emergence, and plant flowering mostly have used observational data collected during the past 50 years (McCarty 2001, Thackeray et al. 2010); however, NHCs can be used to extend observational data back into the 19th and early 20th centuries (Scharlemann 2001). For example, herbarium collections have been used to test for changes in angiosperm flowering times (Primack et al. 2004) and fruiting times for mushrooms (Kauserud et al. 2008).

Shifts in diet can also result from adaptation to climate change, and these shifts are often documented by chemical analysis of material stored in NHCs. For example, an isotopic study of feathers from preserved skins of the rockhopper penguin, Eudyptes chrysocome, allowed the reconstruction of penguin diets from the past 160 years (Hilton et al. 2006), revealing a shift in the trophic level of their prey diet. Similarly, genetic studies of historical collections can be used to estimate historical population sizes (Miller and Waites 2003, Leonard 2008). For example, genetic data from Pleistocene mammals have revealed massive climate-related fluctuations in megafauna population sizes (Barnett et al. 2009).

Climate-related changes in species interactions such as disease or competition can also be studied using NHCs. For example, a survey of historical collections has helped document the spread of chytridiomycosis fungal pathogens on amphibians-a range expansion with serious consequences for amphibian populations that has been linked to climate change (Lips et al. 2008, but see Kilpatrick et al. 2010). Similarly, herbarium specimens were used to document the age of populations of the invasive species Alliaria petiolata (garlic mustard) in eastern North America, and analysis of extant populations showed decline in production of allelopathic compounds (Lankau et al. 2009).

New methods and infrastructures are increasing the payback from research using NHCs. Recent advances in biodiversity informatics are revolutionizing the distribution of NHC data as new pipelines are developed to allow automated integration of information, improving data quality and allowing sophisticated analyses of information from disparate sources (Guralnick et al. 2007, Hill et al. 2009).
Aside from information technology, a broad range of analytical techniques are now available that could not be applied when historical materials were collected. Most important are advances in biochemistry and geochemistry that allow the study of DNA, proteins, isotopes, and the trace element composition of specimens. In many cases, technological development of methods has reduced the barriers to their use on museum specimens. For example, the growing ability to perform biochemical and geochemical analyses with very small samples has greatly reduced objections to destructive sampling (Hausmann et al. 2009), and new imaging methods using computer tomography allow the visualization of internal structures without dissection of material. These advances help overcome issues associated with sampling limited or unique resources.

\section{Challenges and opportunities: Increasing the value of NHC data}

Information associated with NHC objects is often incomplete, imprecise, or inaccurate. Because most collections have grown for reasons other than the support of climate change research, collectors might not have recorded significant information, or former curatorial practices might have allowed information to be separated from collections, with connections later severed by poor information management. In some cases, the links between data and collections objects can be re-created through historical scholarship; for example, studies of collections and other records have reconstructed more complete geographical and biological information on the specimens collected by Charles Darwin, now held in various NHCs (Sulloway 1982, Thomas 2009). Specimen label data may be enriched greatly through the study of associated documentation such as diaries, memoirs, collection logs, and expedition itineraries, which are often available in the archives of NHC institutions, but also may be available from external sources such as the UK Colonial Registers and Royal Navy Logbooks (www.corral.org.uk). Direct linkage of these data sources to specimens using modern collections management systems will provide easy access to valuable additional data related to collections.

Furthermore, collections data need not be perfectly resolved to provide crucial insights on biotic change. For example, establishing the former presence of a species in a region does not require precise georeferencing or collection dates (Stewart 2007). Although most studies of changing body size use highly resolved data, some analyses group data into broader temporal or geographic bins prior to analysis (Meiri et al. 2009). Studies of distribution changes over the past century might require precise geographic information, but the exact date of collection might be less important if, for example, one were comparing only two intervals (Moritz et al. 2008).

Collections are compiled from a broad range of sources, and will always contain inaccuracies and out-of-date information that can be a greater challenge than imprecise information. In some cases, errors can be discovered 
and fixed with further study, most obviously in the case of improved accuracy of taxonomic identifications through examination by experts. Analyses of DNA recovered from NHCs are now able to remedy some data quality deficiencies associated with both taxonomic identifications and provenance (Barnett et al. 2007). In some cases, retrospective georeferencing can help discover mislabeled locality data (Chapman and Wieczorek 2006). In many cases, however, some investment in the improvement of data quality will be required to apply NHC data to climate change research. Were it possible to start from scratch and re-collect the data required for a particular study, there might be value in taking advantage of the information already held in NHCs.

Natural history collections are often spatially and temporally biased (Boakes et al. 2010). Large international museum collections with long histories of collecting tend to have a good spatial representation of material collected from around the world, reflecting past trade and colonial links. However, there is often a temporal bias in NHCs for specimens collected before the 1960s, which reflects the acquisition of large collections from amateur naturalists. Following the decline in popularity of amateur collections of specimens in favor of digital images, this source of material has diminished. International museums now must rely largely on external funding to finance collecting trips by members of their staff, which limits collecting by in-house staff and increases reliance on transfers of material from external researchers. In contrast, national or regional museums are becoming increasingly important as a resource of recently collected, well-documented specimens of national origin. This positive development is particularly noteworthy in countries with high biodiversity but less economic development. The Instituto Nacional de Biodiversidad of Costa Rica (INBio; www.inbio.ac.cr), established in 1989, is a good example of a successful national institute serving as a repository of national biodiversity information, with a collection of more than three million specimens. Development of collections and associated infrastructure in such regions has been encouraged through programs such as the Darwin Initiative, supported by the UK government (darwin.defra. gov.uk), which assist countries that are rich in biodiversity but poor in financial resources to meet their objectives under the Convention on Biological Diversity (www.cbd. int). Biodiversity informatics networks and the digitization of collections objects have great potential to increase the level of expertise in biodiversity-rich countries by dramatically reducing the cost of transferring information from collections-rich countries holding significant historical material (for example, the Solanaceae Source; www.nhm. ac.uk/solanaceaesource).

Even within collections-rich countries, local and university museums are often a repository of important regional materials that supplement the national collections and are a significant source of past distributional and phenological data. The importance of these collections may be overlooked by local governments and university departments, as they are often underresourced and the collections are allowed to deteriorate or be dispersed.

\section{Unlocking the vault}

Identifying subsets of NHC data that, with additional investment, are most likely to contribute to climate change research is a goal best pursued collaboratively by NHC holders and climate change researchers. Each group has differing expertise and priorities to contribute. Climate change researchers can help define potential uses of NHC data, whereas curators can best elucidate what might be possible using existing collections. This process will probably require information about collections that may not be currently available, because collections from areas with high potential for climate change research are likely to be distinct from those used for taxonomic or systematic research, and thus are unlikely to have been prioritized for curation and documentation. For example, collections of large numbers of common taxa are often the most useful as time series for determining species-level responses to climate change, and destructive sampling is more acceptable for common, duplicate, and nontype material. Collections of common material are thus of special value for climate change research; however, they typically have been perceived as of low priority for acquisition or curatorial effort, or have even been identified as prime candidates for disposal. Similarly, unprocessed bulk samples may be ideal for ecological analysis, but these have generally been regarded as being of little use to museum researchers, which constitutes a failure to consider potential applications in climate change research.

Maximizing the potential use of NHCs in climate change research may require major reallocation of resources within collection-holding institutions to encourage basic curation and development of narrative data for collections previously seen as being of negligible value or interest. As a first priority, such collections need to be identified, and information about their size, condition, and completeness of data must be made available to the global change research community. Biodiversity informatics tools assist with discovering useful collections (Guralnick et al. 2007), especially because material is very likely to be held by multiple institutions. The continued growth of federated data sources such as Global Biodiversity Information Facility (www.gbif.org) will facilitate the compilation and use of integrated data sets.

One important outcome of making NHC data available over biodiversity informatics networks should be a greater ability to demonstrate patterns of collections use that are critical for attracting continued funding and for setting curation priorities. However, the very infrastructure that makes data conveniently accessible for global change research has the potential to jeopardize efforts to demonstrate the relevance of NHCs. When collections data from multiple data providers are merged into an integrated system, the contributions of particular sources can be lost. There is an urgent need to maintain the chain of evidence from data providers 
into compilations, not only to allow revised information to flow back to data providers (Hill et al. 2009) but also to ensure a one-to-one mapping of data to specimens, which will maintain replicability of research data and help collections holders give greater support to relevant collections.

Most NHC institutions are seeking to increase their holdings' use in climate change research. Institutional priorities and collections management strategies should invite input from the climate change research community; collections development policies might require updating in response to new uses for collections. For example, collections holders might need to continually assess destructive sampling policies to allow more refined geochemical or biochemical analysis. Natural collections holders need to prioritize digitization efforts for collections with potential for climate change research. In turn, climate change researchers need to be willing to help identify collection curation priorities. Integrity and security of research collections would be improved if researchers were trained in curation and collections maintenance, and by the assurance that new data and specimens are passed back to collections holders for curation and wider dissemination.

Natural history collections should be dynamic repositories of specimens and their associated data. Continuing research produces new information about specimens that is most appropriately cared for over the long term by specimen owners. Data improvement might include taxonomic identification, georeferencing, preparations of material, or the products of geochemical or biochemical analysis. Curating this new information within the institutions responsible for the specimens helps to preserve the tight linkage between specimens and information required to track changing interpretations, which might otherwise be lost in the confusion of transient, project-specific databases. This is a challenge for NHC holders, who in most cases are not equipped to accept large volumes of incoming information. It is also a challenge for NHC users, who must devote resources to sending updated interpretations back to collections holders as research continues. The solution is to put clear structures in place, preferably consistent within and across institutions, and make adherence to those structures a prerequisite for collections use by researchers. Support for data mining within historical collections and collection sampling needs to be built into research project planning from the onset. In addition, taxonomic expertise is often overlooked in project planning stages, as are the resources required for curation of existing or new material.

Collections and supporting staff should be regarded as large-scale research infrastructures analogous to astrophysical observatories or advanced geochemical instrumentation facilities, and users of collections should expect to support this infrastructure. Data improvement will help establish the flow of new information back to collections holders. In our view, NHCs should be community resources maintained by a partnership of users and curators. There is a precedent for this kind of interaction in the archaeological community. In many regions, there is a legal recommendation or requirement to consider the presence of archaeological remains when planning new real estate developments. Preservation might include removing finds for conservation and storage in museum collections. The costs of this work are borne by the project developer. These laws have been a boon for archaeologists because they subsidize the accumulation and curation of new data required to advance science.

\section{New collections: Building time series for the future}

As institutions explicitly devoted to the long-term care of natural history data, NHCs are the natural guardians of the collections and data resulting from the study of biotic response to climate change; they should position themselves to grow their collections of specimens and data as records for the future. Biodiversity researchers, industry, governmental and nongovernmental agencies, and citizen science initiatives are increasingly engaged in the species surveying and monitoring required to understand the biotic response to climate change. Collection curators should take advantage of this opportunity and build collections of physical voucher specimens to ensure taxonomic standards and provide proxy material for future research. However, assimilating the enormous volume of material that could potentially result from worldwide biological monitoring far exceeds the current capacity of collections holders. Priorities should be focused on those voucher specimens necessary to ensure taxonomic control for comparisons, and for new collections to extend both the time series and point collections held in existing collections. Emphasis might also be placed on biota and biomes that remain poorly documented but are likely to experience significant effects from climate change in the near future, such as polar habitats or tropical mountains. Coordination of the efforts of different institutions worldwide should also be a long-term goal.

Natural history institutions might consider adjusting their collections-acquisition and specimen-documentation strategies to emphasize this new use of their infrastructure and ensure that they are able to accommodate the data generated by climate change research. New collections should be sampled, processed, and curated following protocols that facilitate multiple uses without prejudicing unanticipated future uses. For example, many NHC specimens originating from historical sampling programs now have diminished value because they were split into taxonomic subsets without a record of the sample from which the subsets were obtained. Other samples were partially sorted but without records of which taxa were removed, rendering them less useful for multitaxon comparisons. Sample storage standards need careful consideration to maximize samples' potential for later analysis; in particular, curators should avoid the use of preservatives or pesticides that interfere with biochemical analyses, such as formalin and ethanol for wet collections, and mercuric chloride and naphthalene for dry collections. The potential utility of many existing collections is reduced by a lack of data on treatment history. Alternatively, small 
tissue samples could be obtained routinely from incoming material and processed and stored as required for biochemical analysis, while the remainder of the material is stored for traditional anatomical research. Even the physical arrangement of storage or organization of electronic databases can facilitate or hinder the use of NHCs for climate change research (Tingley and Beissinger 2009). In many cases, collections are arranged in a taxonomic order to facilitate comparison of material for systematic research. In contrast, collections arranged by sampling locality or habitat are more convenient for faunal-level analyses. Collection storage and handling processes must be considered in the context of various uses by both internal staff and external researchers.

Adapting collections management procedures and accommodating large volumes of new material takes careful planning and will require institutional flexibility, but this is an opportunity to ensure continued relevance of NHCs to global change research. Collections holders need to set internal priorities with the aim of continuing to be essential resources for contemporary scientific questions. This essay focuses on climate change, but similar messages apply to other research areas in every aspect of biology. Museums and collections should be seen as part of the essential infrastructure of science, necessary for enabling research in highpriority areas. Evolution, systematics, and taxonomy have long been well served by NHCs, but ecology, biodiversity, conservation biology, and many other aspects of biological science could also benefit from greater access to the collections' data. Rethinking NHCs as centers for recording the biosphere's response to climate change will have broader impacts for collections-holding institutions as they continue to evolve.

\section{Acknowledgments}

We are grateful for the insightful comments of Robert Guralnick and three anonymous reviewers. This work was supported by a grant from Strategic Innovation Fund of the Natural History Museum (NHM), London, and is a contribution from the NHM Climate Change Research Group.

\section{References cited}

Andersen T, Carstensen J, Hernández-García E, Duarte CM. 2009. Ecological thresholds and regime shifts: Approaches to identification. Trends in Ecology and Evolution 24: 49-57.

Barnett R, Yamaguchi N, Shapiro B, Nijma V. 2007. Using ancient DNA techniques to identify the origin of unprovenanced museum specimens, as illustrated by the identification of a 19th century lion from Amsterdam. Contributions to Zoology 76: 87-94.

Barnett R, et al. 2009. Phylogeography of lions (Panthera leo) reveals three distinct taxa and a Late Pleistocene reduction in genetic diversity. Molecular Ecology 18: 1668-1677.

Bastos-Silveira C, Lister A. 2007. A morphometric assessment of geographical variation and subspecies in impala. Journal of Zoology 271: 288-301.

Boakes EH, McGowan PJ, Fuller RA, Chang-qing D, Clark NE, O'Connor K, Mace GM. 2010. Distorted views of biodiversity: Spatial and temporal bias in species occurrence data. PLoS Biology 8: e1000385.

Broennimann O, Thuiller W, Hughes G, Midgley GF, Roberts Alkemade JM, Guisan R. 2006. Do geographic distribution, niche property and life form explain plants' vulnerability to global change? Global Change Biology 12: 1079-1093.

[CCSP] Climate Change Science Program. 2009. Thresholds of Climate Change in Ecosystems: A Report by the U.S. Climate Change Science Program and the Subcommittee on Global Change Research. US Geological Survey.

Chapman AD, Wieczorek J, eds. 2006. Guide to Best Practices for Georeferencing. Global Biodiversity Information Facility.

Chen IC, Shiu HJ, Benedick S, Holloway JD, Cheye VK, Barlow HS, Hill JK, Thomas CD. 2009. Elevation increases in moth assemblages over 42 years on a tropical mountain. Proceedings of the National Academy of Sciences 106: 1479-1483.

Eggleton P, Inward K, Smith J, Jones DT, Sherlock E. 2009. A six year study of earthworm (Lumbricidae) populations in pasture woodland in southern England shows their responses to soil temperature and soil moisture. Soil Biology and Biochemistry 41: 1857-1865.

Frey JK. 2009. Distinguishing range expansions from previously undocumented populations using background data from museum records. Diversity and Distributions 15: 183-187.

Gaubert P, Papes M, Peterson AT. 2006. Natural history collections and the conservation of poorly known taxa: Ecological niche modeling in central African rainforest genets (Genetta spp.). Biological Conservation 130: 106-117.

Guralnick R, Van Cleve J. 2005. Strengths and weaknesses of museum and national survey data sets for predicting regional species richness: Comparative and combined approaches. Diversity and Distributions 11: 349-359.

Guralnick R, Hill AW, Lane M. 2007. Towards a collaborative, global infrastructure for biodiversity assessment. Ecology Letters 10: 663-672.

Hausmann A, Hebert PDN, Mitchell A, Rougerie R, Sommerer M, Edwards T, Young CJ. 2009. Revision of the Australian Oenochroma vinaria Guenée, 1858 species-complex (Lepidoptera: Geometridae, Oenochrominae): DNA barcoding reveals cryptic diversity and assesses status of type specimen without dissection. Zootaxa 2239: 1-21.

Hill A, Guralnick R, Flemons P, Beaman R, Wieczorek J, Ranipeta A, Chavan V, Remsen D. 2009. Location, location, location: Utilizing pipelines and services to more effectively georeference the world's biodiversity data. BMC Bioinformatics 10: S3.

Hilton GM, Thompson DR, Sagar PM, Cuthbert RJ, Cherel Y, Bury SJ. 2006. A stable isotopic investigation into the causes of decline in a sub-Antarctic predator, the rockhopper penguin Eudyptes chrysocome. Global Change Biology 12: 611-625.

Kauserud H, Stige LC, Vik JO, Okland RH, Hoiland K, Stenseth NC. 2008. Mushroom fruiting and climate change. Proceedings of the National Academy of Sciences 105: 3811-3814.

Kharouba HM, Algar AC, Kerr JT. 2009. Historically calibrated predictions of butterfly species' range shift using global change as a pseudo-experiment. Ecology 90: 2213-2222.

Kilpatrick AM, Briggs CJ, Daszak P. 2010. The ecology and impact of chytridiomycosis: An emerging disease of amphibians. Trends in Ecology and Evolution 25: 109-118.

Krishtalka L, Humphrey PS. 2000. Can natural history museums capture the future? BioScience 50: 611-617.

Kuussaari M, et al. 2009. Extinction debt: A challenge for biodiversity conservation. Trends in Ecology and Evolution 24: 564-571.

Lankau RA, Nuzzo V, Spyreas G, Davis AS. 2009. Evolutionary limits ameliorate the negative impact of an invasive plant. Proceedings of the National Academy of Sciences 106: 15362-15367.

Leonard JA. 2008. Ancient DNA applications for wildlife conservation. Molecular Ecology 17: 4186-4196.

Lips KR, Diffendorfer J, Mendelson III JR, Sears MW. 2008. Riding the wave: Reconciling the roles of disease and climate change in amphibian declines. PLoS Biology 6: e72.

Lister AM, Stuart AJ. 2008. The impact of climate change on large mammal distribution and extinction: Evidence from the last glacial/interglacial transition. Comptes Rendus Geosciences 340: 615-620.

McCarty JP. 2001. Ecological consequences of recent climate change. Conservation Biology 15: 320-331. 
McElwain JC, Chaloner WG. 1995. Stomatal density and index of fossil plants track atmospheric carbon dioxide in the Paleozoic. Annals of Botany 76: 389-395.

Meiri S, Guy D, Dayan T, Simberloff D. 2009. Global change and carnivore body size: Data are stasis. Global Ecology and Biogeography 18: 240-247.

Mikkelsen PM, Bieler R. 2000. Marine bivalves of the Florida Keys: Discovered biodiversity. Pages 367-387 in Harper EM, Taylor JD, Crame JA, eds. The Evolutionary Biology of the Bivalvia. Geological Society of London Special Publication 177. Geological Society of London.

Miller CR, Waites LP. 2003. The history of effective population size and genetic diversity in the Yellowstone grizzly (Ursus arctos): Implications for conservation. Proceedings of the National Academy of Sciences 100: 4334-4339.

Millien V, Lyons SK, Olson L, Smith FA, Wilson AB, Yom-Tov Y. 2006. Ecotypic variation in the context of global climate change: Revisiting the rules. Ecology Letters 9: 853-869.

Moritz C, Patton JL, Conroy CJ, Parra JL, White GC, Beissinger SR. 2008. Impact of a century of climate change on small-mammal communities in Yosemite National Park, USA. Science 322: 261-264.

Parmesan C. 2007. Influences of species, latitudes, and methodologies on estimates of phenological response to global warming. Global Change Biology 13: 1860-1872.

Parmesan C, et al. 1999. Poleward shifts in geographical ranges of butterfly species associated with regional warming. Nature 399: 579-583.

Peterson AT, Ortega-Huerta MA, Bartley J, Sanchez-Cordero V, Soberon J, Buddemeier RH, Stockwell DRB. 2002. Future projections for Mexican faunas under global climate change scenarios. Nature 416: 626-629.

Primack D, Imbres C, Primack RB, Miller-Rushing AJ, Del Tredici P. 2004. Herbarium specimens demonstrate earlier flowering times in response to warming in Boston. American Journal of Botany 91: 1260-1264.

Pyke GH, Ehrlich PR. 2010. Biological collections and ecological/environmental research: A review, some observations and a look to the future. Biological Reviews 85: 247-266.

Scharlemann JPW. 2001. Museum egg collections as stores of longterm phenological data. International Journal of Biometeorology 45: 208-211.
Stewart JR. 2007. The fossil and archaeological record of the eagle owl in Britain. British Birds 100: 481-486.

Sulloway FJ. 1982. The Beagle collections of Darwin's finches (Geospizinae). Bulletin of the British Museum (Natural History) Zoology Series 43: 49-94.

Thackeray SJ, et al. 2010 Trophic level asynchrony in rates of phenological change for marine, freshwater and terrestrial environments. Global Change Biology 16: 3304-3313.

Thomas BA. 2009. Darwin and plant fossils. The Linnean 25: 24-42.

Thomas CD, et al. 2004. Extinction risk from climate change. Nature 427: 145-148.

Tingley MW, Beissinger SR. 2009. Detecting range shifts from historical species occurrences: New perspectives on old data. Trends in Ecology and Evolution 24: 626-633.

Walther GR, Post E, Convey P, Menzel A, Parmesan C, Beebee TJC, Fromentin JM, Hoegh-Guldberg O, Bairlein F. 2002. Ecological responses to recent climate change. Nature 416: 389-395.

Wheeler D, García-Herrera R. 2008. Ships' logbooks in climatological research. Annals of the New York Academy of Sciences 1146: 1-15.

Willis KJ, Birks HJB. 2006. What is natural? The need for a long-term perspective in biodiversity conservation. Science 314: 1261-1265.

Woodley JD. 1992. The incidence of hurricanes on the north coast of Jamaica since 1870: Are the classic reef descriptions atypical? Hydrobiologia 247: 133-138.

Kenneth G.Johnson (k.johnson@nhm.ac.uk),Phillip B. Fenberg, Adrian M. Lister, Jonathan A. Todd, Jeremy Young, and John R. Stewart are with the Department of Palaeontology, Natural History Museum, in London, United Kingdom. Stephen J. Brooks and Mark Spencer are with the Department of Entomology, Natural History Museum, in London. Adrian G. Glover and Ellinor Michel are with the Department of Zoology, Natural History Museum, in London. Karen E. James is with the Department of Botany, Natural History Museum, in London. Eugenia Valsami-Jones is with the Department of Mineralogy, Natural History Museum, in London. Phillip B. Fenberg is with the Department of Zoology, Oregon State University, in Corvallis. John R. Stewart is with the School of Conservation Science, Bournemouth University, Talbot Campus, in Poole, United Kingdom. 